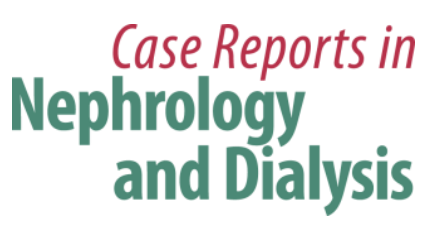

\title{
Sodium Thiosulfate: An Emerging Treatment for Calciphylaxis in Dialysis Patients
}

\author{
Zanzhe Yu Leyi Gu Huihua Pang Yan Fang Hao Yan Wei Fang \\ Department of Nephrology, Renji Hospital, School of Medicine, Shanghai Jiao Tong \\ University, Shanghai, China
}

\section{Key Words}

Hyperparathyroidism · Calcium-phosphorus product · Calcification

\begin{abstract}
Calciphylaxis is a rare but life-threatening complication seen in dialysis patients. We report a case with calciphylaxis and severe secondary hyperparathyroidism. Sodium thiosulfate (STS) was used for treatment in this case. The painful skin ulcers improved significantly soon after treatment, with a slight reduction in the calcium-phosphorus product. Total parathyroidectomy was carried out 6 months after the STS therapy, which successfully solved hyperparathyroidism and the high calcium-phosphorus profiles. Until now, no recurrence of calciphylaxis has been observed during the more than 7 years of follow-up. STS, as a chelating agent for calcium and iron, is an emerging treatment option for calciphylaxis; however, the mechanisms of STS in treating calciphylaxis are not clear. Our case demonstrates that STS treatment did not work through normalizing calcium-phosphorus profiles, although to optimize hyperparathyroidism and to control calcium and phosphorus levels is clearly part of the general treatment of calciphylaxis. The literature on STS treatment for calciphylaxis in dialysis patients was also reviewed.

(C) 2015 S. Karger AG, Basel
\end{abstract}

\section{Introduction}

Calciphylaxis is a rare but life-threatening disease. The risk factors for calciphylaxis include end-stage renal disease (ESRD), dialysis treatment, hyperphosphatemia, hypercalcemia, hyperparathyroidism, diabetes mellitus and female gender. The diagnosis is mainly made clinically and can be confirmed by skin biopsy. However, a biopsy is frequently avoid-

\begin{tabular}{ll}
\hline ARGER 125/s & Wei Fang \\
Department of Nephrology, Renji Hospital, School of Medicine \\
Shanghai Jiao Tong University \\
160 Pujian Road, Pudong New District, Shanghai, 200127 (China) \\
E-Mail fangwei_sh@126.com
\end{tabular}




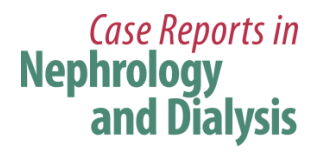

\begin{tabular}{l|l}
\hline \multicolumn{2}{l|}{ Case Rep Nephrol Dial 2015;5:77-82 } \\
\hline DOI: $10.1159 / 000380945$ & $\begin{array}{l}\text { C } 2015 \text { S. Karger AG, Basel } \\
\text { www.karger.com/cnd }\end{array}$ \\
\hline
\end{tabular}

Yu et al:: Sodium Thiosulfate: An Emerging Treatment for Calciphylaxis in Dialysis Patients

ed as it may trigger skin necrosis. Treatment so far includes optimum phosphate and calcium control, treatment of hyperparathyroidism, extensive dialysis and hyperbaric oxygenation. Sodium thiosulfate (STS) is known as an antidote in cyanide intoxication and has recently been used for treating calciphylaxis. We report a case of calciphylaxis in a dialysis patient successfully treated by STS, discussing the mechanisms of the treatment and the relevant issues.

\section{Case Presentation}

We present a male ESRD patient with primary renal diagnosis of glomerular nephritis. He started on peritoneal dialysis (PD) at the age of 60 in 1998. He switched to hemodialysis (HD) 6 years later due to peritonitis. He is neither diabetic nor a smoker. In April 2006, after having been on dialysis for about 8 years, he noticed painful red violaceous ulcerations on the trunk and extremities (fig. 1a). The patient responded poorly to treatment with simple analgesics. At that time, his plasma calcium level was as high as $2.74 \mathrm{mmol} / \mathrm{l}$, and his plasma phosphorus and intact parathyroid hormone (iPTH) levels were $2.49 \mathrm{mmol} / \mathrm{l}$ and 2,122 $\mathrm{pg} / \mathrm{ml}$, respectively. A biopsy of the ulcers was done in August 2006. It showed calcification of the small arteries in the surrounding subcutaneous and adipose tissue, in accordance with the diagnosis of calciphylaxis.

His iPTH level had been $>900 \mathrm{pg} / \mathrm{ml}$ for $>3$ years beforehand, since the time he was on PD (fig. 2). He had been responsive to active vitamin D therapy at first, but treatment was stopped due to the high calcium and calcium-phosphorus product levels. The patient had already been on $1.25 \%$ calcium dialysate and on a calcium and phosphorus restriction diet. One of the parathyroid glands was found to be enlarged at an ultrasound scan. However, he underwent a parathyroidectomy operation due to his poor general condition.

He had tried a course of 4 weeks of aluminum-containing phosphorus binders. It temporarily decreased his phosphorus level but did not improve the skin lesions. Other noncalcium-containing phosphate binders were not available in the country at the time (including cinacalcet).

After consultation with the patient, an off-label use of STS was decided on. STS was infused through a central venous line after HD sessions at a dose of $25 \mathrm{~g} 3$ times during the first week and then at a dose of $12.5 \mathrm{~g} 3$ times per week for 3 months in total. No significant side effect was noted. The skin lesions had significantly resolved (fig. 1b). Before treatment, the patient's plasma calcium level was $2.67 \mathrm{mmol} / \mathrm{l}$, and his plasma phosphorus and iPTH levels were $3.02 \mathrm{mmol} / \mathrm{l}$ and $1,577 \mathrm{pg} / \mathrm{ml}$, respectively. At the end of treatment, the plasma calcium level was $2.38 \mathrm{mmol} / \mathrm{l}$, and his plasma phosphorus level was $2.77 \mathrm{mmol} / \mathrm{l}$ and the iPTH level 2,310 pg/ml. The calcium-phosphorus product had decreased slightly over the 3 months of therapy with some increase in the iPTH level (fig. 2).

Parathyroidectomy was carried out 6 months after STS therapy as the general condition of the patient had improved significantly. Calcium-phosphorus and iPTH levels had dropped after the operation. On the first postoperative day, his plasma calcium level was 1.01 $\mathrm{mmol} / \mathrm{l}$; his plasma phosphorus level was $0.96 \mathrm{mmol} / \mathrm{l}$ and his iPTH level $111 \mathrm{pg} / \mathrm{ml}$. During the 7 years after the operation, plasma calcium, phosphorus and iPTH levels gradually increased. The most recent plasma calcium level measured was $2.13 \mathrm{mmol} / \mathrm{l}$, and the phosphorus and iPTH levels were $2.03 \mathrm{mmol} / \mathrm{l}$ and $241 \mathrm{pg} / \mathrm{ml}$, respectively. There has been no relapse of the skin lesions so far. 


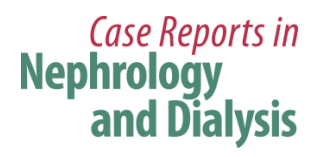

\begin{tabular}{l|l}
\hline \multicolumn{2}{l}{ Case Rep Nephrol Dial 2015;5:77-82 } \\
\hline DOI: 10.1159/000380945 & $\begin{array}{l}\text { ○ 2015 S. Karger AG, Basel } \\
\text { www.karger.com/cnd }\end{array}$ \\
\hline
\end{tabular}

Yu et al.: Sodium Thiosulfate: An Emerging Treatment for Calciphylaxis in Dialysis Patients

\section{Discussion}

Calciphylaxis is an obliterative vasculopathy. It causes ischemia and necrosis of the skin, subcutaneous fat, visceral organs and skeletal muscle. Early lesions resemble livedo reticularis and can appear as indurated, erythematous papules, nodules, plaques or bullae, eventually becoming necrotic foci and painful ulcers. It is associated with a high mortality rate.

The pathogenesis of calciphylaxis is still poorly understood. There is a hypothesis of a 2stage process. The first stage involves vascular injury, characterized by mural calcification, intimal hyperplasia and endovascular fibrosis. In the second stage, additional vascular damage is triggered by clinical events. The second hit can be local trauma, hypotension or thrombosis. It leads to the development of an ischemic infarct, dystrophic calcification or ulceration. Histological findings include a mixed inflammatory infiltrate, a giant cell reaction and panniculitis with subcutaneous calcium deposits, and adipose tissue necrosis.

The treatment of calciphylaxis includes wound care, cessation of warfarin therapy (if used), idealizing calcium and phosphate levels and treating hyperparathyroidism (if existing). Non-calcium-containing phosphate binders like sevelamer and lanthanum carbonate are superior to calcium-containing phosphate binders in these patients. Parathyroidectomy is a promising way of treating hyperparathyroidism, and ulcer healing, pain relief and survival benefit in dialysis patients with calciphylaxis have been reported [1]. For those who are not surgical candidates, cinacalcet can be used. Intensified dialysis may help in some dialysis patients. STS is an emerging treatment option for calciphylaxis.

STS has a small molecular weight of $248\left(\mathrm{Na}_{2} \mathrm{~S}_{2} \mathrm{O}_{3}\right)$ and a serum half-life of $15 \mathrm{~min}$ in patients with normal renal function. In patients with renal failure, STS is thought to be eliminated via biliary secretion. Thiosulfate salts of calcium have a 250- to 100,000-fold higher solubility than other calcium salts, such as those of phosphate and oxalate [2]. Dialysis can remove STS. The medical use of STS includes cyanide intoxication, humoral calcinosis $[3,4]$ and nephrolithiasis [2]. It was first used to treat calciphylaxis in 2004 [5]. Over the last 10 years, a series of reports show that it is an effective and relatively safe treatment for both HD and PD patients $[6,7]$.

Calciphylaxis is a life-threatening condition. Once ulcerations develop, the mortality rate is as high as $80 \%$ [8]. Since 2004, a series of case reports have been published. The largest study evaluating STS in dialysis patients is a multicenter study on 27 patients from Austria [9]. Most studies showed a rapid resolve of symptoms. However, in the largest cohort study of 27 patients, the mortality rate was still as high as 52\% during a median follow-up of 101 days. Clearly, randomized controlled trials are needed to confirm the clinical benefit of the therapy.

The mechanisms of STS in treating calciphylaxis are far from clear. STS induces calcium removal through chelation, and the dysregulation of the calcium and phosphorous metabolism and hyperparathyroidism is clearly one of the risk factors in calciphylaxis. However, our observation confirmed that STS did not work through normalizing the calcium-phosphorous product or iPTH levels. After administering STS, the calcium-phosphorous product was reduced slightly but was still much higher than the recommended level and, if anything, the iPTH level was even higher despite the dramatic and quick resolve of the symptoms. This phenomenon is actually in accordance with data from an animal study [10]. There was a quick decrease in ionized calcium $15 \mathrm{~min}$ after STS application but no significant decrease in calcium later on. The same study also showed a significant increase in urine calcium excretion after STS application, which, in the end, would reduce total body calcium load. In our anuric patient, the gradually reduced calcium level could be a result of the combination of mobilizing calcium to the circulation and the concurrent measures of intensive and low- 


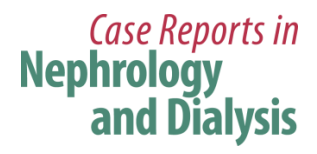

\begin{tabular}{l|l}
\hline \multicolumn{2}{l|}{ Case Rep Nephrol Dial 2015;5:77-82 } \\
\hline DOI: $10.1159 / 000380945$ & $\begin{array}{l}\text { C } 2015 \text { S. Karger AG, Basel } \\
\text { www.karger.com/cnd }\end{array}$ \\
\hline
\end{tabular}

Yu et al.: Sodium Thiosulfate: An Emerging Treatment for Calciphylaxis in Dialysis Patients

calcium HD. STS also exhibits antioxidative and vasodilation properties [11] which may contribute to the rapid resolve of the symptoms. The effect of STS of preventing crystal formation and vascular calcification $[10,12,13]$ may also have contributed to the quick response. It is not dependent on the plasma calcium level either.

The empirical prescription of STS indicates a dose of 25 g given intravenously 3 times per week after HD in HD patients. In the present case, $25 \mathrm{~g}$ were used for the first week and then $12.5 \mathrm{~g}$ for the rest of the therapy. Actually, the best prescription of STS for calciphylaxis is still not clear. In the study by Farese et al. [14], a low and variable bioavailability of oral STS application was reported. On the other hand, the authors also agreed that this was difficult to understand as, despite the very low oral bioavailability of STS, oral STS at comparable doses in their study was reported to successfully prevent renal stones [15], the progression of calciphylaxis [16] and nephrocalcinosis [17]. For PD patients, both the intravenous and intraperitoneal use of STS has been reported $[6,18]$. However, the possibility of chemical peritonitis during intraperitoneal use was raised in another study [6].

As a small molecule, STS can be cleared through dialysis, which may be the reason why most studies have administered STS after HD. However, Zitt et al. [9] noticed an additional survival benefit with the intradialytic application (in the last hour of HD) of STS compared to that after dialysis. The authors suggested that the application of STS during the last hour of dialysis, when dialysate sodium and bicarbonate can be appropriately adapted to counteract the potential STS-induced sodium and acid load, may avoid side effects. However, due to the retrospective and multicenter nature of the study, the difference may be a result of center effect.

The intravenous doses given in the case reports varied from 5 to $75 \mathrm{~g}$ each time. On the other hand, according to the pharmacokinetic simulations, HD frequency and duration markedly changed the STS doses for the same target AUC of the 25-gram thrice-weekly empiric prescription with the HD regimen to thrice weekly for $4 \mathrm{~h}$ per section. The weekly dose varied from 75 to $245 \mathrm{~g}$ [19]. Thus, the therapeutic window of STS is not clear in the first place. A serum concentration of STS between 5 and $10 \mathrm{mmol} / \mathrm{l}$ was used in an animal study to demonstrate the calcium chelate properties of STS [10]. According to the pharmacokinetics study by Farese et al. [14], such high concentrations would be achieved only for $30 \mathrm{~min}$ when the usual dose of $25 \mathrm{~g}$ of STS was given to dialysis patients off-HD. The ideal dose of STS needs further study.

One of the concerns of STS treatment is its negative impact on bone integrity. As an inhibitor of vascular calcification, it is important to realize that it also inhibits hydroxyapatite formation in bone. Pasch et al. [10] noticed that STS lowered bone strength in treated animals compared to normal controls. It is also known that STS induces metabolic acidosis [10, 12]. The accumulation of thiosulfuric acid was thought to be responsible for the anion gap. Inducing acidosis is thought to be one of the therapeutic mechanisms of STS. However, it clearly causes more problems in ESRD patients.

In conclusion, STS is an emerging treatment for calciphylaxis, and its mechanism does not depend on normalizing calcium and phosphorus profiles. Well-designed randomized controlled trials are essential at this stage.

\section{References}

1 Llach F: The evolving pattern of calciphylaxis: therapeutic considerations. Nephrol Dial Transplant $2001 ; 16: 448-451$.

2 Yatzidis H: Successful sodium thiosulphate treatment for recurrent calcium urolithiasis. Clin Nephrol 1985;23:63-67. 
Yu et al.: Sodium Thiosulfate: An Emerging Treatment for Calciphylaxis in Dialysis Patients

3 Kyriakopoulos G, Kontogianni K: Sodium thiosulfate treatment of tumoral calcinosis in patients with endstage renal disease. Ren Fail 1990;12:213-219.

4 Papadakis JT, Patrikarea A, Digenis GE, Stamatelou K, Ntaountaki I, Athanasopoulos V, Tamvakis N: Sodium thiosulfate in the treatment of tumoral calcifications in a hemodialysis patient without hyperparathyroidism. Nephron 1996;72:308-312.

-5 Cicone JS, Petronis JB, Embert CD, Spector DA: Successful treatment of calciphylaxis with intravenous sodium thiosulfate. Am J Kidney Dis 2004;43:1104-1108.

6 New N, Mohandas J, John GT, Ratanjee S, Healy H, Francis L, Ranganathan D: Calcific uremic arteriolopathy in peritoneal dialysis populations. Int J Nephrol 2011;2011:982854.

7 Baldwin C, Farah M, Leung M, Taylor P, Werb R, Kiaii M, Levin A: Multi-intervention management of calciphylaxis: a report of 7 cases. Am J Kidney Dis 2011;58:988-991.

8 Fine A, Zacharias J: Calciphylaxis is usually non-ulcerating: risk factors, outcome and therapy. Kidney Int 2002;61:2210-2217.

-9 Zitt E, Konig M, Vychytil A, Auinger M, Wallner M, Lingenhel G, Schilcher G, Rudnicki M, Salmhofer H, Lhotta K: Use of sodium thiosulphate in a multi-interventional setting for the treatment of calciphylaxis in dialysis patients. Nephrol Dial Transpl 2013;28:1232-1240.

10 Pasch A, Schaffner T, Huynh-Do U, Frey BM, Frey FJ, Farese S: Sodium thiosulfate prevents vascular calcifications in uremic rats. Kidney Int 2008;74:1444-1453.

11 Hayden MR, Goldsmith DJ: Sodium thiosulfate: new hope for the treatment of calciphylaxis. Semin Dial 2010;23:258-262.

-12 Adirekkiat S, Sumethkul V, Ingsathit A, Domrongkitchaiporn S, Phakdeekitcharoen B, Kantachuvesiri S, Kitiyakara C, Klyprayong P, Disthabanchong S: Sodium thiosulfate delays the progression of coronary artery calcification in haemodialysis patients. Nephrol Dial Transplant 2010;25:1923-1929.

O’Neill WC: Treatment of vascular calcification. Kidney Int 2008;74:1376-1378.

Farese S, Stauffer E, Kalicki R, Hildebrandt T, Frey BM, Frey FJ, Uehlinger DE, Pasch A: Sodium thiosulfate pharmacokinetics in hemodialysis patients and healthy volunteers. Clin J Am Soc Nephrol 2011;6:14471455.

15 Asplin JR, Donahue SE, Lindeman C, Michalenka A, Strutz KL, Bushinsky DA: Thiosulfate reduces calcium phosphate nephrolithiasis. J Am Soc Nephrol 2009;20:1246-1253.

16 Musso CG, Enz P, Vidal F, Gelman R, Di Giuseppe L, Bevione P, Garfi L, Galimberti R, Algranati L: Oral sodium thiosulfate solution as a secondary preventive treatment for calciphylaxis in dialysis patients. Saudi J Kidney Dis Transplant 2008;19:820-821.

$\checkmark 17$ Agroyannis B, Tzanatos H, Vlahakos DV, Mallas E: Does long-term administration of sodium thiosulphate inhibit progression to renal failure in nephrocalcinosis? Nephrol Dial Transplant 2001;16:2443-2444.

$\checkmark 18$ Dethloff SB: Calcific uremic arteriolopathy: treatment with intraperitoneal sodium thiosulfate in a patient on peritoneal dialysis. Nephrol Nurs J 2012;39:323-325, 347.

-19 Singh RP, Derendorf H, Ross EA: Simulation-based sodium thiosulfate dosing strategies for the treatment of calciphylaxis. Clin J Am Soc Nephrol 2011;6:1155-1159.
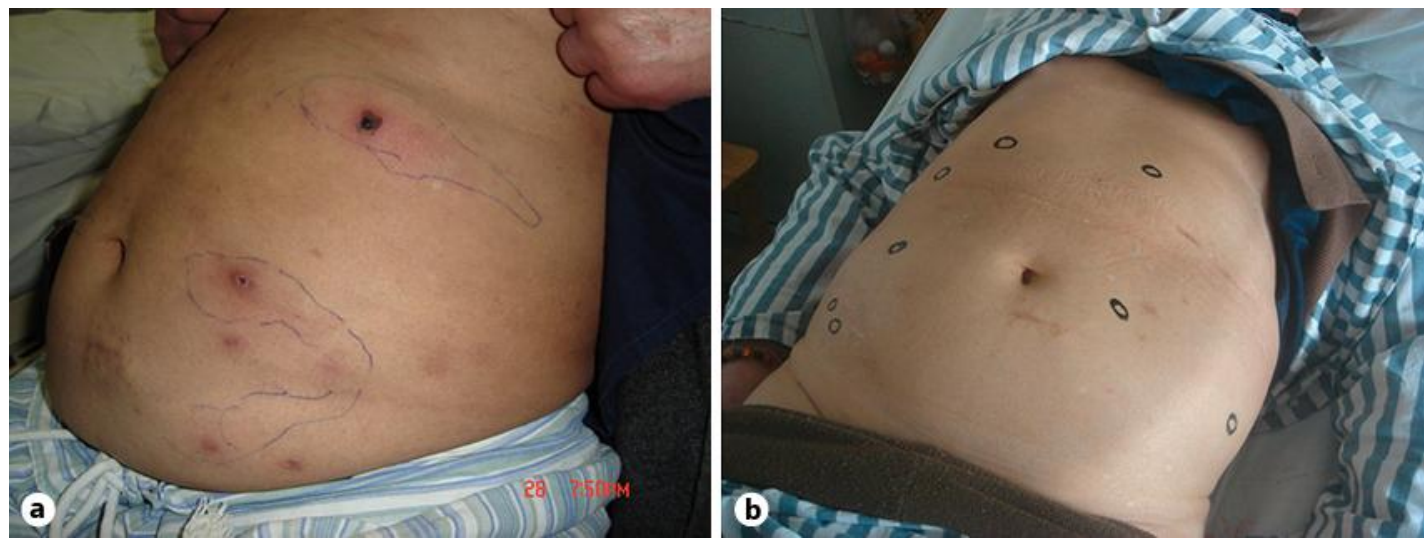

Fig. 1. Skin lesions before (a) and after (b) treatment. 
Case Reports in

Nephrology

and Dialysis
Case Rep Nephrol Dial 2015;5:77-82

2015 S. Karger AG, Basel www.karger.com/cnd

Yu et al.: Sodium Thiosulfate: An Emerging Treatment for Calciphylaxis in Dialysis Patients

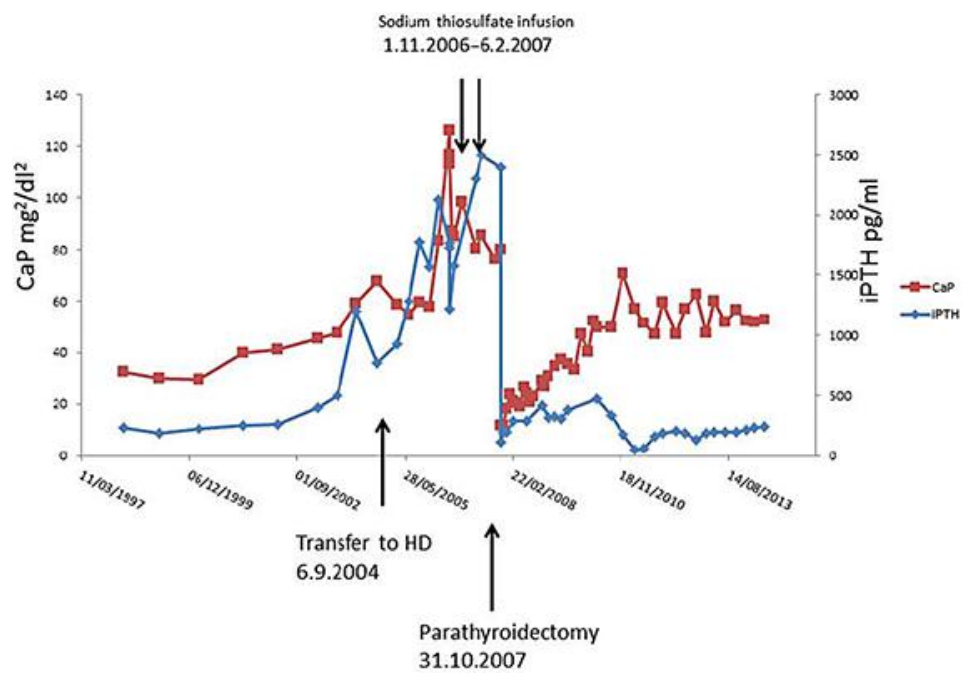

Fig. 2. Calcium-phosphate (CaP) and iPTH levels. 